Derecho \& Realidad

Núm. 23 • I semestre de 2014

Facultad de Derecho y Ciencias Sociales, UPTC

ISSN: 1692-3936

\title{
Acción colectiva en defensa de los derechos de consumidores $y$ usuarios
}

\author{
Collective action to defend the rights \\ of consumers and users
}

Lilia Fernanda Benavides Burbano*

Andrés Murcia González**

\section{Resumen}

El presente escrito tiene por objeto estudiar el reconocimiento de los derechos de los consumidores en países como España y Colombia. En el primer caso, la Constitución española de 1978, en su artículo 51 encomienda a los "poderes públicos» la protección y fortalecimiento de aquellos derechos; en Colombia, la Constitución Política de 1991, en su artículo 78 reconoce de manera explícita los derechos del consumidor.

Como segundo paso en este proceso se analizan los desarrollos legislativos sobre el tema en los dos países. Hay que resaltar que las pautas que rigen el sistema de protección de estos derechos pueden ser guiadas para España y Colombia en estos fundamentos: seguridad y calidad de los productos, protección de intereses económicos y sociales, información correcta y suficiente, educación y formación, representación, consulta y participación, y protección en situaciones de inferioridad. Señaladas las características

Docente de la Universidad de Nariño, estudiante de Doctorado de la Universidad Carlos III de Madrid-España. Correo electrónico: fernandabena@gmail.com

** Abogado asesor de la Asociación de Protección de Consumidores y Usuarios de Madrid, estudiante de Doctorado de la Universidad Carlos III de Madrid-España. Correo electrónico: amurcia_2005@yahoo.es 
generales de protección a los usuarios, se describen aspectos de los mecanismos de protección que hacen efectivo el derecho en mención, mediante un análisis comparado entre las dos legislaciones.

\title{
Palabras clave
}

Consumidores, usuarios, derechos, mecanismos de protección, análisis comparado.

\begin{abstract}
This document aims to study the recognition of the rights of consumers in countries like Spain and Colombia. In the first case, the Spanish Constitution of 1978, Article 51, commits to the public powers the protection and strengthening of those rights. In Colombia the Constitution of 1991, article 78, makes an explicit recognition of the rights of the consumer.

As a second step in this process are studied and analyzed legislative developments on the issue in the two countries. It must be emphasized that the guidelines that govern the system of protection of these rights can be guided to Spain and Colombia on this foundation: safety and quality of products, protection of economic and social interests, correct and sufficient information, education and training, representation, consultation and participation, and protection in situations of inferiority. Highlighted general characteristics of protection to users, aspects of the protection mechanisms that give effect to the right in question are described, through a comparative analysis between the two laws.
\end{abstract}

\section{Key words}

Consumers, users, rights, protective mechanism, comparative analysis. 


\section{Introducción}

En varios ordenamientos jurídicos, el reconocimiento explícito de los derechos de los consumidores y usuarios ha sido reciente, pues con antelación a dicho reconocimiento en la mayoría de los casos aparecían sólo algunas manifestaciones en los códigos civiles y de comercio, haciendo referencia a los derechos y obligaciones de los consumidores en el ámbito privado.

En la década de los sesenta en Estados Unidos, durante el gobierno de John F. Kennedy se inicia la toma de conciencia en torno a los derechos de los consumidores. El mandatario, al respecto, pronunció el siguiente discurso ante el congreso de su país: "Ser consumidor, por definición, nos incluye a todos. Somos el grupo económico más grande en el mercado, que afecta y es afectado por casi todas la decisiones económicas públicas y privadas, pero es el único grupo importante cuyos puntos de vista a menudo no son escuchados" (Pereña, 2005).

Con la entrada en vigencia de las actuales Constituciones, ya es clara la enunciación de "los derechos de los consumidores", como derecho subjetivo, con categoría autónoma, muestra de esto son los casos de España y Colombia, como dos de los países más abanderados en la promoción y protección de los derechos colectivos. En España, "la enunciación explícita de los derechos de los consumidores y usuarios, no tiene lugar hasta la promulgación de la Constitución de 1978, cuyo artículo 51 viene a encomendar a los "poderes públicos" la protección y fortalecimiento de aquellos derechos" (Gómez, 1994, p. 15). En el caso colombiano, la norma relativa a la protección de consumidores de la Constitución de 1991, se consagra en su artículo 78, que establece: "La ley regulará el control de calidad de bienes y servicios ofrecidos y prestados a la comunidad, así como la información que debe suministrarse al público en su comercialización. Serán responsables, de acuerdo con la ley, quienes en la producción y en la comercialización de bienes y servicios, atenten contra la salud, la seguridad y el adecuado aprovisionamiento a consumidores y usuarios. El Estado garantizará la participación de las organizaciones de consumidores y usuarios en el estudio de las disposiciones que les conciernen. Para gozar de este derecho las organizaciones deben ser representativas y observar procedimientos democráticos internos".

A estos contenidos constitucionales, se añadió el posterior desarrollo legislativo que vino a complementar el estatuto jurídico de protección de este grupo. En España en 1984, se elaboró la Ley General para la Defensa de Consumidores y Usuarios, cuyos preceptos han sido objeto de desarrollo por normas específicas (por ejemplo: Ley de Garantía de Bienes de Consumo, Ley de Condiciones Generales de la Contratación). En Colombia, figuran leyes tales como: Ley 142/94 sobre Servicios Públicos Domiciliarios, Ley 37/93 de Telecomunicaciones, la Ley 472/98 sobre Acciones 
Populares y de Grupo, la que actualmente constituye el medio más eficaz para la defensa de los usuarios.

Bajo las anteriores regulaciones, el ámbito de protección de los consumidores, tanto en España como en Colombia, se podría resumir en: (i) Seguridad y calidad de los productos, (ii) protección de intereses económicos y sociales (iii), información correcta y suficiente, (iv) educación y formación, (v) representación, consulta y participación, y, (vi) protección en situaciones de inferioridad.

Después de señalar características generales de la protección de los usuarios, pasaremos a describir algunos aspectos de los mecanismos para hacer efectivo el derecho en mención, a través de un análisis comparado entre los ordenamientos de los países anteriormente mencionados, y así finalizar con una propuesta de reforma a la acción española de cesación, que a nuestro juicio, haría de ésta un procedimiento más eficaz, atendiendo a los buenos resultados que han tenido estos mecanismos, en el caso colombiano.

En el ordenamiento jurídico español, cuando un consumidor ve lesionados sus derechos, puede ser protegido a través de distintas vías. Algunas de las vías más importantes de protección son: reclamación en el establecimiento, reclamaciones ante organismos públicos de protección al consumidor, protección por asociaciones de consumidores, entre otros. Atendiendo al objeto de este trabajo nos concentraremos en la protección de los derechos de los usuarios en la vía civil, y más concretamente en un procedimiento novedoso que se encarga de proteger intereses de grupo: la acción colectiva. Lo relativo al juicio verbal y al juicio ordinario queda excluido, en tanto estos procesos tienen como finalidad, en principio, la defensa de los consumidores en tanto personas individuales.

\section{La acción colectiva de cesación en España}

La acción colectiva es definida por la doctrina como una acción declarativa o de condena, encaminada a la protección de intereses colectivos o difusos, o generales o públicos, incluso cuando se trate de intereses intrínsecamente individuales pero con relevancia colectiva. En cuanto a la legitimación activa, en el ámbito español (y en gran parte también europeo) "las acciones colectivas surgen con dos premisas, Legitimación Activa no total sino ampliada a un grupo de entidades tasadas y efectos de las sentencias ampliados más allá de los personados pero no frente a todos" (Pineda, 2006, p. 273-303). Así, la Ley de Garantías de Bienes de Consumo de 2003, establece en su artículo 12, que podrán ejercitar la acción de cesación: a) El Instituto Nacional de Consumo y los Órganos o Entidades correspondientes de las Comunidades Autónomas y de las Corporaciones Locales competentes en materia de defensa de los consumidores. b) Las Asociaciones de Consumidores y Usuarios que reúnan los requisitos establecidos en la LGDCU o, en su caso, en la legislación 
autonómica en materia de defensa de los consumidores. c) El Ministerio Fiscal y, d) Las Entidades de otros Estados miembros de la Unión Europea constituidas para la protección de los intereses colectivos y de los intereses difusos de los consumidores que están habilitadas mediante su inclusión en la lista publicada a tal fin en el Diario Oficial de las Comunidades Europeas. Es importante destacar que algún sector de la doctrina distingue entre los intereses colectivos y difusos, sin profundizar en este debate, en resumen, se consideran colectivos los intereses comunes a una colectividad de personas, pero solo cuando existe un vínculo jurídico entre componentes del grupo, como ocurre con las sociedades, los sindicatos, entre otros. En cambio, se consideran difusos los intereses que sin fundarse en un vínculo jurídico se basan en factores de hecho genéricos y contingentes, accidentales y mutables, como habitar en la misma zona, consumir el mismo producto, entre otros. Para Lidón Montón García, la diferencia se encuentra en la determinación de los sujetos implicados: fácil para los intereses colectivos y compleja, al menos, para los intereses difusos, esta distinción tendría efectos en lo que respecta a la legitimación. Estos efectos se ponen de manifiesto en los artículos 11.2 LEC y 11.3 LEC, que establecen que en materia de intereses colectivos existe legitimación de las asociaciones de consumidores identidades legalmente constituidas que tengan por objeto la defensa o protección de los usuarios, mientras que para defender intereses difusos, sólo pueden actuar las asociaciones.

\section{La acción popular y de grupo en Colombia}

De acuerdo con lo estipulado en la Constitución de 1991, en sus artículos 88, 89 y 90, y la ley 472/98, la acción popular es el medio procesal para la protección de los derechos e intereses colectivos, que está instituida para evitar el daño contingente; hacer cesar el peligro, la amenaza, la vulneración o el agravio de un derecho o interés colectivo o para restituir las cosas a su estado anterior siempre que sea posible. En resumen, dicha acción puede ser preventiva o restitutoria. Tienen trámite preferencial, en relación con los demás acciones que conozca el funcionario judicial, con excepción de las acciones de habeas corpus, de tutela y de cumplimiento. A diferencia de la acción española, la legitimación activa de dicha acción, en Colombia, puede ser ejercida: a) Por toda persona natural o jurídica; b) Por las organizaciones no gubernamentales, populares, cívicas o de índole similar; c) Por las entidades públicas que cumplan funciones de control, intervención o vigilancia, siempre que la amenaza o vulneración a los derechos e intereses colectivos no se haya originado en su acción u omisión; d) Por el procurador general de la Nación, el defensor del Pueblo y los personeros distritales y municipales, en lo relacionado con su competencia; e) Por los alcaldes y demás servidores públicos que por razón de sus funciones deban promover la protección y defensa de estos derechos e intereses.

Los legitimados para ejercer las acciones populares pueden hacerlo por sí mismos o por quien actúe en su nombre, sin la necesaria intervención de abogado. 
El Consejo de Estado ha desarrollado varias tesis en el tema de la legitimación para ejercer las acciones populares. La tesis de mayor acogida ha establecido que cualquier persona independientemente de que pertenezca o no a la comunidad afectada con la vulneración o amenaza del derecho colectivo, puede interponer una acción popular (Consejo de Estado, 2001). Por otro lado, la acción de grupo o de clase es la garantía constitucional de carácter judicial, que permite a una pluralidad de personas constituidas como grupo, acudir ante la justicia para reclamar la reparación del daño ocasionado a un derecho constitucional fundamental, a un derecho o interés colectivo o a un derecho subjetivo de cada uno de los miembros de ese conjunto de personas, cuando el daño, producido por una misma causa, perjudica a todos los accionantes (Corte Constitucional, 1999). Las acciones de grupo proceden cuando con la acción u omisión de las entidades públicas, de las personas privadas que desempeñan funciones administrativas y de las demás personas particulares se causa un daño a los derechos de un número plural o a un conjunto de personas. Lo anterior, exige que los miembros del grupo deban reunir condiciones uniformes respecto de la misma causa que origino los perjuicios individuales para dichas personas y respecto de todos los elementos que configuren la responsabilidad. La acción de grupo se ejercerá exclusivamente para obtener el reconocimiento y pago de la indemnización de perjuicios. Es importante señalar que la existencia del grupo no está determinada por el daño, sino que este se ha formado alrededor de una situación común en la que se han colocado sus miembros y con ocasión de la cual, posteriormente, todos (o algunos de ellos) sufren un daño. Dichas acciones podrán ejercitarlas: a) Las personas naturales o jurídicas que hubieren sufrido un perjuicio individual, cuando la acción sea procedente y no esté caducada; b) El defensor del Pueblo en nombre de cualquier persona que se lo solicite o que se encuentre en situación de desamparo o de indefensión, sin perjuicio del derecho que le asiste a los interesad; c) Los personeros municipales y distritales en las mismas situaciones en que lo puede hacer el defensor del Pueblo. Para los efectos del ejercicio de las acciones de clase, el grupo deberá estar integrado al menos por veinte (20) personas. El actor o quien actúe como demandante representa a las demás personas que hayan sido afectadas individualmente por los hechos vulneratorios, sin necesidad de que cada uno de los interesados ejerza por separado su propia acción, ni haya otorgado poder.

\section{Propuesta de reforma a la acción colectiva de cesación española}

Dispersión normativa. El ordenamiento jurídico español ha sido objeto de varias iniciativas de regulación en materia de acciones colectivas. Estos intentos que se habían desarrollado con anterioridad al año 2000 se vieron frustrados por la falta de una regulación procesal específica. Lo anterior se subsanó parcialmente con el artículo 11 de la nueva LEC. Sin embargo, se debe tener presente que esta reforma legislativa deja, a nuestro juicio, ámbitos jurídicos (por ejemplo el medio ambiente), con una regulación asistemática en lo que concierne a la defensa de intereses colectivos. Con 
relación a lo anterior, Pineda Salido afirma que: "En definitiva el sistema español de acciones colectivas cuenta con una clara dispersión normativa a nivel sustantivo y con unas graves deficiencias procesales, muchas de ellas no sólo no han resultado resueltas por la última modificación, la Ley 39/2002, sino que en muchos casos han sido agrandadas" (2006, p. 273-303). Para mejorar este aspecto, resulta interesante tener presente la regulación colombiana en materia de acciones populares y de grupo, que se caracteriza por su coherencia y concentración normativa, en tanto que cualquier asunto sustantivo que afecta a un colectivo (medio ambiente, salubridad pública, acceso a servicios públicos, etc.) puede solventarse a través de la vía procesal consagrada en la Ley 472/98.

Legitimación activa limitada. A nuestro parecer, la legitimación activa prevista por la ley, es muy restringida en la medida en que la lista de entidades legitimadas es taxativa y no permite la habilitación absoluta de cualquier interesado. Este elemento es contrario a la esencia de las acciones colectivas, que desde su origen fueron concebidas como instrumentos de defensa de los intereses de todos los ciudadanos. De igual manera, consideramos que limitar la legitimación, en el caso de los intereses difusos, a las asociaciones de consumidores más representativas resulta inadecuado en tanto la ley, establece que dicha condición se adquiere al ser parte en el Consejo de Consumidores y Usuarios, cuyos requisitos son bastante restrictivos: Número muy elevado de asociados, presencia en numerosas Comunidades Autónomas y amplia capacidad económica. En torno a esta limitante, consideramos que dicha legitimación debe ser más amplía, extendiéndose a distintas plataformas y a todos los ciudadanos. De esta forma se fortalece la capacidad para dar eficacia, ante los tribunales, a los derechos que los individuos tienen reconocidos por ley, en su condición de consumidores y usuarios.

El incentivo y condena en costas. El incentivo consagrado en la ley, es considerado doctrinariamente como un estímulo que se le otorga al actor popular, por la interposición de la acción y su gestión hasta la culminación. Dicha figura se ha fijado con el objeto de impulsar a la sociedad a que denuncie las actividades del estado o de particulares, que afecten a los derechos colectivos. La cuantía es determinada por el juez discrecionalmente. En España, el número de acciones colectivas en materia de consumidores, desde el 2000 es reducido, un mecanismo eficaz para la defensa de intereses de grupo sería el establecimiento de la figura del incentivo. El riesgo que se corre con la implementación de esta institución, es el aumento exagerado de la litigiosidad injustificada, pero este efecto no deseado puede combatirse, desde nuestro punto de vista con el mantenimiento de la condena en costas establecida en los artículos 241.2 y 394 LEC.

Fondo para la defensa de los derechos e intereses colectivos. Actualmente, en España la protección de estos derechos no resulta del todo satisfactoria, en la medida 
Derecho y Realidad

en que las Asociaciones de consumidores no tienen la suficiente capacidad económica para asumir los costos de una acción colectiva. Como alternativa a esta situación, consideramos beneficiosa la instauración de un Fondo para la defensa de los derechos e intereses colectivos, cuyas funciones serían la difusión de estos derechos, y sus mecanismos de protección; la evaluación de las solicitudes de financiación que le sean presentadas y la escogencia de aquellas que a su juicio sería conveniente respaldar económicamente de acuerdo con los criterios determinados en la ley; la financiación de las acciones colectivas y la consecución de las pruebas; administración de las indemnizaciones ordenadas en la sentencia que concede una acción colectiva.

Finalmente, este Fondo podría ser gestionado por el Instituto Nacional del Consumo, siendo el organismo de la administración general del Estado competente o por el órgano correspondiente en las comunidades autónomas.

\section{Referencias}

Colombia. Ley 472/98 Acciones Populares y de Grupo.

Colombia. Constitución Política de 1991.

Colombia. Consejo de Estado. (2001, 14 de dic.). Sección Quinta. Exp. 2001-0237-01. M.P. Roberto Medina López.

Colombia. Corte Constitucional. (1999, 14 de abr.). Sentencia C-215. M. P. Dra. Martha Victoria Sáchica Méndez.

Defensoría del Pueblo y Embajada Real de los Países Bajos. (2004). Los derechos colectivos y su defensa a través de las acciones populares y de grupo. Bogotá: Imprenta Nacional.

De León, Alicia et al. (2007). Derechos de los Consumidores y Usuarios Doctrina (normativa, jurisprudencia y formularios). ( $2^{\text {a }}$ ed.). Valencia: Tirant Lo Blanch.

España. Ley 23/ 03 de Garantías de Bienes de Consumo.

España. Constitución de 1978.

Gómez, J. (1994). Los derechos de los consumidores y usuarios. Dykinson: Madrid.

Guillén, J. (2000). El marco jurídico constitucional de la Ley 11/1998, de 9 de julio, de protección de los consumidores de la Comunidad de Madrid. Madrid: La Ley.

Montón, L. (2004). Acciones Colectivas y acciones de cesación. Madrid: Fareso.

Pereña, I. (2005). Los derechos de los consumidores (Conoce tus derechos). Madrid: Boletín oficial del Estado.

Pineda, L. \& Lunas, M. J. (2006). Publicaciones del Consejo General del Poder Judicial. (Cuadernos de derecho judicial 20/2003). Donostia, San Sebastián: s.n. 